\title{
The Hemispheric Specialization of the Human Brain and Its Application to Psychoanalytic Principles
}

David A. Scola, M.D.

Thomas Jefferson University Hospital

Follow this and additional works at: https://jdc.jefferson.edu/jeffjpsychiatry

Part of the Psychiatry Commons

Let us know how access to this document benefits you

\section{Recommended Citation}

Scola, M.D., David A. (1984) "The Hemispheric Specialization of the Human Brain and Its Application to Psychoanalytic Principles," Jefferson Journal of Psychiatry. Vol. 2 : Iss. 1 , Article 5.

DOI: https://doi.org/10.29046/JJP.002.1.001

Available at: https://jdc.jefferson.edu/jeffjpsychiatry/vol2/iss1/5

This Article is brought to you for free and open access by the Jefferson Digital Commons. The Jefferson Digital Commons is a service of Thomas Jefferson University's Center for Teaching and Learning (CTL). The Commons is a showcase for Jefferson books and journals, peer-reviewed scholarly publications, unique historical collections from the University archives, and teaching tools. The Jefferson Digital Commons allows researchers and interested readers anywhere in the world to learn about and keep up to date with Jefferson scholarship. This article has been accepted for inclusion in Jefferson Journal of Psychiatry by an authorized administrator of the Jefferson Digital Commons. For more information, please contact: JeffersonDigitalCommons@jefferson.edu. 


\title{
THE HEMISPHERIC SPECIALIZATION OF THE HUMAN BRAIN AND ITS APPLICATION TO PSYCHOANALYTIC PRINCIPLES
}

\author{
DAVID A. SCOLA, M.D.
}

Volumes of research have been accumulated over the past decade concerning hemispheric specialization of the human brain. Likewise, over the past century, psychoanalysts have painstakingly unraveled through their clinical observation many of the mysteries of intrapsychic functions. Yet little has been written concerning attempts to integrate these seemingly divergent viewpoints.

It was Freud's hope that a neural basis for his clinical observations and psychological explanations of the human mind would eventually be established. This was not possible in his day, however, so this idea was gradually abandoned. With the advent of computers and high technology, perhaps it is time for a reexamination of this premise. For example, Position Emission Tomography, with its unique ability to observe the brain in action via the brain's metabolic utilization of radioactively labeled glucose may open as yet undreamed of frontiers in the neurosciences. The technological advances being used to unlock the mysteries of the brain may also be able to help elucidate the secrets of human behavior.

Indeed, psychiatry has benefited from the technology of the latter half of this century. The wide acceptance and usage of psychotropic medications attests to this fact. Yet, dynamic psychiatry and biological psychiatry have very little points of intersection. There seems to be no cross fertilization of ideas and methods. This can only be to the detriment of both practitioners and their patients.

This paper is an attempt to reconcile two seemingly unrelated areas, i.e., hemispheric specialization of the human brain and psychoanalytic use of dreams, their interpretation and free association. It is hoped that through the examination of these well established psychoanalytic techniques that they may be seen in a somewhat different perspective, the laterality paradigm. In many ways it echoes traditional psychoanalytic concepts and may represent the neuropsychological underpinnings of what Freud so astutely observed about the nature of the human psyche. Hopefully, the psychoanalytic and laterality perspectives can mutually enhance each other and through this enhancement, help further unlock and uncover the mysteries of the human brain and its functioning.

We will initially consider the function of the cerebral hemispheres in the human brain both in the adult and child. Likewise the role of the corpus callosum will be examined, primarily from a developmental perspective. From there, the psychoanalytic principles mentioned above will be discussed.

Dr. Scola is a fourth-year resident in Psychiatry. 


\section{Brief Overview of Right Hemisphere Properties}

The right hemisphere, in general, seems to express itself in a non-linguistic manner and preferentially processes affective material (1). The right hemisphere is also dominant for tactile and proprioceptive sensations (2), orientation in space, artistic and musical endeavors, body image and recognition of faces. It processes information more diffusely than does the left hemisphere, being specialized for the integration of many inputs at once (3). Its mode of operation has been termed holistic, relational, simultaneous, and appositional $(3,4)$.

\section{Brief Overview of Left Hemisphere Properties}

The left hemisphere is most notable for containing the neural substrate for the expression and comprehension of language (Broca's and Wernicke's areas respectively). It specializes in the perception and labeling of material that can be coded linguistically (5). It organizes and categorizes material into discrete temporal and sequential units, processes mathematical and analytical functions and mediates verbal concept formation $(6,7)$. Its mode of operation has been described as linear, sequential, analytical and logical (3).

These functional modes of operation of the cerebral hemispheres have neuroanatomical correlates. A relatively higher concentration of white matter in the right hemisphere as compared with the left suggests a greater degree of neuronal interconnection (8). This observation supports the suggestion (2) that the receptotopic distribution of information across the cortex is focal and discrete in the left hemisphere but more diffuse and generalized in the right hemisphere.

\section{The Right Hemisphere and Emotion}

Emotionality appears to be most intimately related with subcortical limbic structures (9). However, these limbic structures maintain intimate neural connections with the right hemisphere. The right frontal and temporal regions are actually outgrowths of limbic nuclei and have maintained cytoarchitectural as well as functional similarities to limbic cortex (10). One way of determining right frontal lobe activation is by observation of lateral eye movements as the contralateral frontal eye fields initiate their movement. Many studies $(1,11,12)$ have used the directionality of lateral eye movements as indicators of hemispheric activation with Schwartz et. al. (1) finding that spatial-emotional questions result in leftward eye movements due to right frontal lobe activation.

Studies of neurological impairment also support the role of the right hemisphere in emotion. One study (13) showed that right hemisphere damage impaired story recall specifically when the story had emotional content. In another study (14), patients with right or left temporoparietal lesions were asked to judge the content of spoken sentences and the emotional mood of the speaker; both groups did well on content, but the right lesioned group was significantly impaired in the emotional judgment. A 
deficit in comprehension of emotion in a speaker's tone of voice was again demonstrated by Tucker, et. al. (15), which further showed that right hemisphere damage impaired ability to communicate emotion through tone of voice. It was also demonstrated that right hemisphere damage causes an individual to have difficulty in expressing emotion through normal tone of voice inflections in everyday interactions (16).

The same results have been obtained with normal college students (17). A task requiring judgments of sentence content and the speaker's tone of voice was administered monaurally via the right or left ears (most input is processed by the contralateral hemisphere). A left ear superiority for the emotional judgments was interpreted as further indication of the right hemisphere's importance to affective comprehension.

The right hemisphere also seems to evaluate emotional events negatively. One study (18) presented motion pictures to the visual half-fields through the use of special contact lenses. Films presented to the left half-fields were rated more negatively. Another study (19) examined affective responses to TV programs. Frontal lobe EEG recordings showed a differential effect with left frontal activation during positive affect and right frontal activation during negative affective responses. In another study (20) subjects generated thoughts, feelings or images associated with positive or negative experiences. The results again showed preferential right frontal activation for negative experiences and left frontal activation for positive ones.

A remarkable case study (21) illustrates the negativeness that the right hemisphere may possess. A 12-year-old right-handed epileptic boy who was also bilingual was commissurotomized (surgical sectioning of the corpus callosum) at age 11 for intractable seizures. One test required him to rate words on a goodness-badness scale with 1 representing good and 7 representing bad. The right hemisphere consistently rated words worse than the left. For example the word Mother was rated 1 by the left and 6 by the right hemisphere. Sex received the same ratings. On the testing day described above, the subject's affect was anxious and he was generally "hyperactive and aggressive" (not further described). On another testing day when there was very little left-right discrepancy of word evaluations, the subject was described as "calm, tractable and appealing." Thus, negative behavioral and mood changes were accompanied by a left-right hemisphere discordancy. The right hemisphere seemed to be in a bad mood. In this subject, therefore, the right hemisphere was intimately involved with negatively rated, emotional material. Except for the last mentioned study all previously mentioned references pertained to adults.

\section{Laterality in Children}

Many of the studies of laterality in children parallel those of adults. Long before language skills have developed there is an asymmetry of electrical cortical responses to verbal and non-verbal stimuli. A study (22) found that newborns (mean age $=5.8$ months) showed a greater electrical activation over the left hemisphere in response to verbal stimuli while non-verbal stimuli (a musical chord) resulted in greater right hemisphere activation. These findings were replicated (23) for 3- and 4-month-old 
infants. Battro (24) found logical and spatial operations (as measured by Piagetian tests) to be lateralized in opposite hemispheres in children 4-8 years of age. Right hemisphere specialization for tactile-spatial processing in 4- and 5-year-olds were found (25) in an experiment involving the visual recognition of shapes haptically explored by either hand. Moreau and Milner (26) found a right hemisphere superiority in 5-year-olds for identification of unilateral, bilateral and double simultaneous ipsilateral and contralateral tactile stimulation of the face and hands. Ingram (27) studied children 3-5 years of age and found that the left hand (right hemisphere) performed better at hand posture and finger spacing tasks. Children of ages 5, 7 and 11 years were found to have a right hemisphere superiority in the visual recognition of faces presented briefly to the right or left visual field (28). A literature search revealed only one study pertaining to emotional stimuli in infants and children. A study of 10-month-old infants showed greater left frontal activation when shown a videotape of an actress generating a happy face. No difference was found between the hemispheres in the frontal regional in response to sad stimuli (actress generating a sad face).

In adults, the right hemisphere seems to preferentially process negative affective stimuli, while the left hemisphere is more activated with positive affective stimuli. Only the latter seems to be true in this study of 10-month-old infants. Much more data are needed, however, and this area seems to be one which requires much more research.

\section{The Corpus Callosum in Children}

The corpus callosum is the neural structure that principally mediates the interhemispheric transfer of information. The anterior commissure functions in the same manner but to a much lesser extent. Apparently the corpus callosum is one of the last systems to begin and to complete myelination. In humans, myelination does not begin until the end of the first year (30), is substantially advanced by age 4, largely completed by age 6 , and continues to slowly myelinate until at least age 10 (31). This anatomical immaturity is paralleled by functional immaturity.

Galin et. al. (30) concluded that 3-year-olds have more difficulty comparing tactile information between the two hemispheres than within a hemipshere and that this difference is reduced by the age of 5. Joseph and colleagues (32) found interhemispheric communication to be so poor that when pictorial stimuli are presented tachistoscopically to the right hemisphere, children 4 years of age will respond when questioned, with large information gaps which they erroneously fill with confabulatory responding. It thus appears that the left hemisphere of a young child has, at best, incomplete knowledge of the contents and activity that occur in the right (33).

From what has so far been discussed, it seems that in childhood, many experiences are preferentially processed in the right hemisphere. However with poor language refinement in the infant and child, many such experiences are difficult to remember as they were either not verbally encoded at all or only crudely so. In addition to the problem of encodement, another significant impediment to childhood remembrances is the poor interhemispheric communication. 


\section{Left Hemispheric Ignorance of Right Hemisphere Contents}

What is the fate of a memory encoded in a non-verbal manner? A carotid amytal study (34) can perhaps be helpful in answering this question. The patients involved in this study were being evaluated for suspected tumors and ranged in age from 38-64. Prior to angiography they were injected with $100-150 \mathrm{mg}$ of 10 percent sodium amobarbital into the left common carotid artery and approximately two minutes later were presented an object (out of view) to actively palpate with their left hand. Immediately after palpation, none were able to name the object (as was expected since the left hemisphere was drugged and thus the speech centers inactivated). After the drug effects had subsided, none of the patients could verbally recall the tactile stimulus. Seventy-five percent, however, were able to immediately recognize the correct choice in a visual multiple choice test and usually did so by pointing with the left hand. This study seems to indicate the difficulty of the adult brain to verbally recall an experience encoded in a non-verbal manner. This type of finding has also been demonstrated in split-brain experiments i.e., in patients who underwent cerebral commissurotomy for treatment of intractable seizures (35). A nude pin-up was flashed tachistoscopically to the right hemisphere of a female patient with a split-brain. She blushed and giggled immediately afterwards. When asked what she saw she replied that she only saw a flash of light and continued giggling. When again asked why she was giggling, she just replied that Dr. Sperry had "some machine." Another patient was having great difficulty performing a block design task with his right hand (left hemisphere). In trying to match a corner of the design, the right hand corrects one of the blocks, and then shifts it again, apparently not realizing it was correct. The left hand (right hemisphere) darts out, grabs the block and restores it to the correct position. Thus in all of these situations, the right hemisphere had access to information that the left did not. Again, this seems to be analogous to the situation in childhood discussed above.

\section{Relative Right Hemisphere Autonomy}

There is suggestive evidence from the previously mentioned study by Le Doux et. al. (21) that the right hemisphere has a mind of its own. It was found that in this commissurotomized patient, the right hemisphere has a sense of self for it knows its name. In response to further questioning it was found that the right hemisphere has feelings and a sense of the future, for it can describe its mood and knows what day tomorrow is. It has aspirations and goals for the future, for it can describe its occupational choice (which by the way, differed from the left hemisphere response).

It thus seems compelling in view of these studies, to postulate that within all of us exist two repositories of experiences and memories which can influence behavior and judgment. In essence, there seem to be two minds in us.

\section{Dreams}

Since 1953 when Aserinsky and Kleitman (30) first discovered the EEG evidence of different sleep stages, REM sleep has been associated with dreaming. The mode of 
cognition in dreaming is usually of the primary process type; mainly non-verbal image representations, and violations of ordinary temporal sequencing (37). Fenichel (38) states that primary process thinking is carried out more through pictorial, concrete images, whereas the secondary process is based more on words. Bogen $(4,39)$ is of the belief that the right hemisphere uses a non-verbal mode of representation, utilizing images, and that the right hemisphere reasons by a non-linear mode of association rather than by syllogistic logic. It seems, then, that the right hemisphere mode of functioning and the phenomenology of dreams have much in common.

This commonality is further seen in studies of brain-injured patients. One study (40) described three patients who spontaneously reported cessation of dreaming following right posterior brain injuries. Impaired visual imagery in the waking state was also found. In this reference, four other cases in the older neurological literature are cited in which depression of dreaming and waking visual imagery were associated with right parietooccipital lesions. This cessation of dreaming appears in split-brain patients also (4). Several of these commissurotomized patients reported that they no longer had any dreams, in contrast to frequent vivid dreaming before the operation. One way of interpreting this curious finding is that if the right hemisphere is the source of dreams, the left hemisphere would be unable to verbally report the dreams, since it no longer had access to them. Hoppe (41) found that ". . . patients after commissurotomy reveal a paucity of dreams, fantasies, and symbols. Their dreams lack the characteristics of dream work; their fantasies are unimaginative, utilitarian, and tied to reality."

EEG and cerebral blood flow findings (42) seem to indicate a right hemisphere dominance for REM sleep. Other studies $(43,44)$ have found evidence of hemispheric dissociation during REM sleep, resulting in a functional disconnection between the hemispheres. This situation is analogous to that previously described for young children, that the left hemisphere seems to have impaired access to the contents of the right both in the dream state and in childhood. This may account for the difficulty that many people seem to have in remembering their dreams. Some, in fact, absolutely insist that they never dream. Cohen's data (45) suggest an increase in left hemisphere participation in dream experience later in the night. Perhaps this may account for the observation that many dreams that are remembered seem to occur in the early morning hours just prior to awakening.

But what of dream interpretation? How is this to be understood in the context of cerebral laterality? If one views the right hemisphere as the repository of negative affectively tinged memories that may be difficult to verbally encode, and even more difficult to communicate interhemispherically (in children at least), and that these memories may influence attitudes and behavior, then perhaps an explanation can be attempted. One of the main goals of psychoanalysis as put forth by Freud was making the unconscious conscious. If viewed in this way with the right hemisphere as the rough equivalent of the unconscious, and the left hemisphere as equivalent to the conscious then it seems that some sense can be made of dream interpretation in the context of cerebral laterality. The dream becomes the expression of right hemisphere mentation which largely concerns itself with the types of memories described above. Insofar as present day events resonate with affectively tinged memories of an earlier time, they 
are incorporated as day residue. Yet both in the dream and in the childhood origins of the memories which form the basis of the dream, there is little integration with the left hemisphere, which is still largely ignorant of the contents. Through the associations to the visual imagery of the dream in a systematic, verbal manner, the unconscious becomes conscious, i.e., the left hemisphere has further access to the memories that it previously was largely unaware. Through the combined efforts of both analyst and patient, it is as if a right hemisphere memory or experience is extruded and placed under the scrutinizing gaze of the left hemisphere. In this manner, interhemispheric communication is enhanced. The very situations which largely contributed to the left hemisphere's ignorance are overcome viz: 1) lack of verbal encodement, 2) poor interhemispheric communication. The affect must become integrated with the logic. But what about free association. Can it too be understood in this context?

\section{Free Association}

Free association is the fundamental rule of psychoanalysis. It involves "a particular condition of mind, one which approximates an intermediate state between sleep and wakefulness in which judgmental faculties are held in abeyance and thoughts flow in the form of fantasies and pictorial images. It . . . indicates closeness to the type of thinking that exists in the unconscious" (46). From what has beeen previously stated in this article, "judgmental faculties" can be taken as a left hemisphere function while pictorial images are mediated by the right hemisphere. It has also been found that the seemingly haphazard associations are actually connected via affect, not logic. In other words, the right hemisphere appears to be intimately involved in the production of free associations if the roles of the hemispheres as presented in this paper are followed. To the best of my knowledge, there have not been any EEG studies of people undergoing the free associative process. However, a closely related state has been examined, viz., meditation. The techniques of meditation seem to be designed purposely to avoid logical, verbal and rational reactions to perceived events. Sustaining attention on one object as in one-pointed concentration, naming or noting stimuli successively as they enter consciousness as in Buddhist mindfulness (the similarity to free association is striking), and maintaining a visual mode of imagery combined with concentration as in tantric practice, all appear to reduce abstract thought and verbal associations (47). If attention is a right hemisphere mediated function as Mesulam and Geschwind (48) contend, then it, along with visual imagery and the avoidance of verbal logic and rationality, seem to indicate that in meditative techniques the left hemisphere is switched off and the right hemisphere is turned on. Both Glueck and Strobel (49) and Erlichmann and Wiener (50) have EEG evidence to this effect. Their data suggest that the initial stages of meditation (the first one to two minutes) are associated with greater deactivation of the left hemisphere and hence a relative right hemisphere dominance.

As Sloane (46) points out, a mere flow of words in a stream-of-consciousness style cannot lead to understanding. Free association must be combined with self-observation and interpretation. In other words, free association is a dynamic active process in the 
sense that the products of the associative process that are arrived at in a relaxed state are subjected to a more active, intensive scrutiny in the self-observing and interpreting process. This leads us to a similar conclusion as the one that we arrived at when we examined dreams in the context of cerebral laterality, viz., that right hemisphere mentation is actively examined by the analytic left hemisphere (or observing ego), and in this way interhemispheric communication is enhanced and the unconscious becomes conscious.

Another area that may be fruitfully examined via the laterality paradigm is that of defense mechanisms of the ego. The female patient of Dr. Sperry's who blushed at the tachistoscopically presented nude picture (35) might be said to be denying or repressing if viewed psychodynamically. Is splitting the result of impaired interhemispheric communication where the right hemisphere influences the bad view and the left hemisphere the good one? Are isolation of affect and intellectualization, defenses commonly used by the obsessive-compulsive, also a result of poor interhemispheric communication? A few studies have attempted to answer these questions. Gur \& Gur (11) found that subjects who characteristically looked to the left (right hemisphere activation) in response to questions scored higher on a defense mechanism cluster that included repression and denial. In a study of hysterical and obsessive-compulsive personalities (51) there was significantly more left looking among the hysterical subjects. Stern (52) found that both right-handed and left-handed patients experienced a higher proportion of left-sided conversion symptoms (weakness, paralysis, sensory loss or numbness) than would be expected by chance. These findings are intriguing and point to directions for future research.

Many questions remain unanswered and it is hoped that psychodynamic theory will utilize the insights obtained through the technological, neurological and biological approaches to the study of human behavior. In this way, perhaps we can better understand the child within the man.

\section{REFERENCES}

1. Schwartz, GE, Davidson, FJ and Maer, F: Right hemisphere lateralization for emotion in human brain: Interaction with cognition. Science 190: 286-288, 1975

2. Semmes, J: Hemispheric specialization: a possible clue to mechanism. Neuropsychologia 6: $11-26,1968$

3. Ornstein, R: The Psychology of Consciousness. Harcourt Brace Jovanovich, Inc., 1977

4. Bogen, JE: The other side of the brain: II. An appositional mind. Bull Los Angeles Neurol. Soc. 34: 135-162, 1969

5. Luria, AR: The Working Brain. Basic Books, N.Y., 1973

6. Critchley, M: The Parietal Lobes. Hafner, N.Y., 1953

7. Dimond, SJ, and Beaumont, JG: Experimental studies of hemisphere function in the human brain. In Hemisphere Function in the Human Brain. John Wiley, N.Y., 1974

8. Tucker, D: Lateral brain function, emotion and conceptualization. Psychol Bull Vol. 89, No. 1: 19-46, 1981

9. Scoville, WB: Neurophysiological symposium: Limbic lobe in man. Journal of Neurosurgery 11: 64-66, 1954 
10. Maclean, RD: The limbic system and its hippocampal formation: Studies in animals and their possible application to man. Journal of Neurosurgery 11:29-44, 1954

11. Gur, RE and Gur, RC: Defense mechanisms, psychosomatic symptomatology and conjugate lateral eye movements. Journal of Consulting and Clinical Psychology 43: 416-420, 1975

12. Tucker, DM, Roth, RS, Arneson, BA and Buckingham, V: Right hemisphere activation during stress. Neuropsychologia 15: 697-700, 1977

13. Wechsler, AF: The effect of organic brain disease on the recall of emotionally charged versus neutral narrative text. Neurology 23: 130-135, 1973

14. Heilman, KM, Scholes, R, and Watson, RT: Auditory affective agnosia: Disturbed comprehension of affective speech. Journal of Neurology, Neurosurgery, and Psychiatry 38: 69-72, 1975

15. Tucker, DM, Watson, RG, And Heilman, KM: Affective discrimination and evocation in patients with right parietal disease. Neurology 26: 354, 1976

16. Ross, ED, and Mesulam, MM: Dominant language functions of the right hemisphere? Prosody and emotional gesturing. Archives of Neurology 36: 144-148, 1979

17. Safer, MA, and Leventhal, H: Ear differences in evaluating emotional tone of voice and of verbal content. Journal of Experimental Psychology: Human Perception and Performance 3: $75-82,1977$

18. Dimond, SJ, Farrington, L and Johnson, P: Differing emotional response from right and left hemisphere. Nature 261: 690-692, 1976

19. Davidson, RJ: Hemispheric specialization for affective processes in normals: Behavioral and electrophysiological studies. Paper presented at the meeting of the Society for Biological Psychiatry, Atlanta, GA, May 1978

20. Davidson, RJ, Schwartz, GE, Saron, C, Bennett, J, and Goleman, D: Frontal versus parietal EEG asymmetry during positive and negative affect. Paper presented at the meeting of the Society for Psychophysiological Research, Madison, Wisc., Sept. 1978

21. LeDoux, J, Wilson, D, Gazzaniga, M: A divided mind: Observations on the conscious properties of the separated hemispheres. Annals of Neurology 2: 417-421, 1977

22. Molfese, DL: Cerebral asymmetry in infants, children and adults: auditory evoked responses to speech and musical stimuli. J Acoust Soc Am 53: 363, 1973

23. Best, C, Hoffman, H, Glanville, B: Development of infant ear asymmetries for speech and music. Perception and Psychophysics 31: 75-85, 1982

24. Battro, A: Hemispheric lateralization in the development of spatial and logical reasoning in left and right-handed children. Archives De Psychologie 49: 83-90, 1981

25. Etaugh, C, Levy, R: Hemispheric specialization for tactile-spatial processing in preschool children. Perceptual and Motor Skills 53: 621-622, 1981

26. Moreau, T, Milner, P: Lateral differences in the detection of touched body parts in young children. Developmental Psychology 17: 351-356, 1981

27. Ingram, D: Motor asymmetries in young children. Neuropsychologia 13: 95-102, 1975

28. Young, A, Ellis, H: An experimental investigation of developmental differences in ability to recognize faces presented to the left and right cerebral hemispheres. Neuropsychologia 14: 495-498, 1976

29. Davidson, R, Fox, N: Asymmetrical brain activity discriminates between positive and negative affective stimuli in human infants. Science 218: 1235-1236, 1982

30. Galin, D, Johnstone, J, Narell, L, Herron, J: Development of the capacity for tactile information transfer between hemispheres in normal children. Science 204: 1330-1331, June 1979 
31. Yakovlev, P, Lecours, A: The myelogenetic cycles of regional maturation of the brain. In A. Minkowski (Ed.), Regional Development of the Brain in Early Life. Phila., Davis, 1967

32. Joseph, R, Gallagher, R, Kahn, J and Holloway, W: Two brains one child: Confabulation and interhemispheric transfer in children aged 3-7 and 10. Manuscript to be submitted for publication

33. Joseph, R: The neuropsychology of development: Hemispheric laterality, limbic language, and the origin of thought. Journal of Clinical Psychology 38: 4-33, 1982

34. Risse, G, Gazzaniga, M: Well-kept secrets of the right hemisphere: A carotid amytal study of restricted memory transfer. Neurology 28: 950-953, 1978

35. Sperry, R: Hemisphere deconnection and unity in conscious awareness. Am. Psychol. 23: 723-733, 1968

36. Aserinsky, E, Kleitman, N: Regularly occurring periods of eye motility and concomitant phenomena during sleep. Science 118: 273, 1953

37. Galin, D: Implications for psychiatry of left and right cerebral specialization. Arch Gen Psychiatry 31: 572-582, 1974

38. Fenichel, O: The Psychoanalytic Theory of Neurosis. New York, W.W. Norton and Co., Inc., 1945, p. 47

39. Bogen, JE: The other side of the brain: I Dysgraphia and dyscopia following cerebral commissurotomy. Bull Los Angeles Neurol Soc 34: 135-162, 1969

40. Humphrey, M, Zangwill, O: Cessation of dreaming after brain injury. J Neurol Neurosurg Psychiatry 14: 322-325, 1951

41. Hoppe, K: Split brains and psychoanalysis. Paper presented at meetings of the Institute for Psychoanalysis, Chicago, Nov. 1975, and of the Southern California Psychoanalytic Society, Feb. 1976

42. Goldstein, L, Stoltzfus, N, and Gardocki, J: Changes in interhemispheric amplitude relationships in the EEG during sleep. Physiology and Behavior 8: 811-815, 1972

43. Burdick, J, Laszlo, M, Goldstein, L: Quantitative analysis of the EEG and heart rate variability in normal subjects: Wakefulness, Stage IV and REM sleep. Psychophysiology 5: 224, 1968

44. Tomka, T, Nagypal, T, Sipos, K: Analysis of REM and transition stages of sleep. EEG and Clinical Neurophysiology 34: 356, 1973

45. Cohen, DB: Changes in REM dream content during the night: Implications for a hypothesis about changes in cerebral dominance across REM periods. Perceptual and Motor Skills 44: 1267-1277, 1977

46. Sloane P: Psychoanalytic Understanding of the Dream. New York: Jason Aronson, Inc., 1979 , p. 19

47. Earle, JBB: Cerebral laterality and meditation: A review of the literature. The Journal of Transpersonal Psychology 13: 155-173, 1981

48. Mesulam, M, Geschwind, N: On the possible role of Neocortex and its limbic connections in the process of Attention and Schizophrenia: Critical cases of inattention in man and experimental anatomy in monkey. J Psychiat Research 14: 249-259, 1978

49. Glueck, B, Stroebel, C: Biofeedback and meditation in the treatment of psychiatric illness. Comprehensive Psychiatry 16: 303-321, 1975

50. Erlichman, H, Wiener, M: EEG asymmetry during covert mental activity. Psychophysiology 17: 228-235, 1980

51. Smokler, I, Shevrin, H: Cerebral lateralization and personality style. Arch Gen Psychiatry 36: 949-954, 1979

52. Stern, D: Handedness and the lateral distribution of conversion reactions. The Journal of Nervous and Mental Disease 164: 122-128, 1977 